\title{
Engaging medical students during COVID-19 - challenges and novel opportunities for clinical training.
}

\author{
Mohideen, M. R.
}

\begin{abstract}
Introduction: The COVID-19 pandemic has disrupted undergraduate clinical training in an unprecedented manner. With face-face student-patient interaction severely curtailed and hands-on training limited, the pandemic has upended experiential learning in a major way.

Methods: The aim of this review was to examine the challenges faced and actions taken by medical schools and explore opportunities to overcome the loss of clinical training due to constrains by the public health measures to the COVID-19 crisis. The relevant literature was searched in PubMed, and Google Scholar using specific keywords, e.g., "COVID-19 "medical education," "challenges," and "opportunities."
\end{abstract}

Results: Four themes were explored; initial response, mitigation measures, innovative solutions and future plans. Halting undergraduate clinical training was widespread except in a few countries where student's graduation was fast-tracked to serve the national healthcare workforce or assigned to nonclinical work. The loss of experiential learning was replaced by successfully transitioning to emergency remote online teaching through lectures, videos, quizzes and webinars. These are perceived as stopgap measures and falls short of replacing the authentic face to face learning in a clinical environment. Several innovative immersive methods were showcased using telehealth and virtual reality technologies and found to be useful and meaningful solutions to the loss of clinical interactions in the circumstances. Although these are attractive technological solutions, it is unlikely to be adopted in low resource setting until cost and training issues are resolved. Future plans will need to take the new-normal post covid environment into consideration and embrace the emergent technology to mitigate against further disruption.

Conclusions: Significant widespread disruption to medical education has impacted clinical learning and delayed graduation. The rapid institutional response has mitigated the impact and kept students educationally engaged. The pandemic has highlighted that the immersive clinical experience in wards and interactive small group sessions are not easily replaceable. The challenge is to develop an innovative post-COVID medical education plan that will ensure a continuity in learning with academic competency.

Key words: clinical training, medical students, covid-19, virtual learning

"He who studies medicine without books sails an uncharted sea, but he who studies medicine without patients does not go to sea at all." William Osler

Department of Internal Medicine, IMU Clinical Campus, 6, Jalan Indah, Taman Sri Kenangan, 83000, Batu Pahat, Johor, Malaysia

Email: mohamed rifdy@imu.edu.my

\section{Introduction}

With the announcement of the global pandemic of COVID-19 by WHO on March 2020, a string of measures was adopted by countries to mitigate the spread of the infection (WHO, 2020). Isolation of cases and self-quarantine of contacts were instantly enforced. Physical or social distancing and wearing masks in public quickly became common place and public gathering limited. Academic meetings,

DOI: http://doi.org/10.4038/seajme.v14i2.246

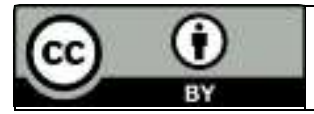

(C) SEAJME. This is an Open Access article distributed under the terms of the Creative Commons Attribution License (http://creativecommons.org/licenses/by/4.0/), which permits unrestricted use, distribution, and reproduction in any medium, provided the original author and source are credited 
international and local conferences went virtual, postponed or cancelled. Clinical training of medical and other health professionals was suspended without a plan in USA and many other countries (AAMC, 2020; MQA, 2020).

Under normal circumstances, medical students visit hospital wards, clinics and other healthcare facilities to take histories directly from patients, join ward rounds and learn from experienced clinicians. Students are also expected to either observe, assist or perform under supervision several listed bedside procedures to improve their practical skills. Many ward procedures are opportunistic with few pre-planned. When medical students are not present in ward or clinic or unable to join in a ward round, a significant aspect of their practical training is affected.

In many training programmes of healthcare professions, there is no viable alternative to learning from direct patient care. In a few, such as counselling courses, a virtual environment may be acceptable in a telehealth setting. Moreover, institutions have an ethical obligation to make sure their graduates are well prepared to enter the workforce and provide care for patients. Students need to put in a minimum number of hours of direct face-face patient interactions to develop confidence and practice numerous clinical skills. These immersive experiential learning experiences are considered so vital that the generally licensing authorities are not willing to forego this requirement even in the final years of clinical training. This strict and unrelenting requirement of certification of clinical competency has prevented some students from graduating on time.

The hesitancy of medical schools and health authorities to get students directly involved in patient care to assist the overworked hospitals staff and into the front line of this emergency crisis is understandable Although young students are at the lower spectrum of risk from complications by virtue of their age and good health, the risk of falling ill from the infection with direct patient contact is very real with severe complications and deaths reported among healthcare workers worldwide (Ing et al. 2020).Shortages of personal protective equipment add to the risk of exposing medical students to the wards.

\section{Methods}

A literature search was carried out on PubMed and Google Scholar using the terms coronavirus OR SARS-CoV-2 OR COVID-19 AND medical education* OR medical student*.
The search yielded 134 journal articles. Of these, articles referring to the preclinical period, postgraduate or residency period were excluded and 26 met the inclusion criteria. Additionally, the references cited in the selected articles were manually searched and added to the final list. There was no attempt to evaluate the quality of the publication or study design. Original reports, surveys, reviews, commentaries, perspectives, short or special communications and letters on covid-19 pandemic were reviewed.

The principal focus of this review paper was to examine the challenges and opportunities faced by medical schools in implementing alternatives to clinical learning in response to the covid-19 crisis.

\section{Results}

This review probed four themes. The first was the immediate response of the medical school administration and licensing authorities to the crisis. Secondly, to document the alternative methods and modes of clinical learning that were implemented. Next, to explore the adoption of innovative and novel methods to continue student engagement in the clinical environment and finally to synthesise the proposed plans and suggestions for future consideration.

\section{Immediate response}

Medical schools had to make sudden plans to transit to alternatives to clinical training as it was imperative to continue to engage the students in the interim period. Clinical training sites shrunk as teaching hospitals were assigned to deal with the healthcare emergency. Many medical schools halted clinical training altogether resulting in heavy disruption to the programmes. Clinical clerkships were shortened, or postponed, and clinical rotation schedules revamped with assessments deferred and modified. (Samarasekera et al., 2020). Electives were suspended or modified to allow students to work on local projects. The immersive nature of clinical learning presented a unique challenge as online engagement alone will not satisfy both the student and the licencing authorities.

Few notable exceptions were in place for medical students in Australia, New Zealand, UK and Italy. The Medical Deans of Australia and New Zealand announced that clinical students were allowed to continue to remain in their clinical placements assisting staff in non-covid care in hospitals, operating theatres and community while following national guidelines 
for safety and under careful supervision (Medical Deans of Australia and New Zealand, 2020). Similarly, in an unprecedented move, the General Medical Council allowed final-year medical students in the UK to apply for early provisional registration to assist the National Health Service workforce during the pandemic. (British Medical Association, 2020). In Italy too, the government at the height of the pandemic, let final year students forego mandatory exams and to work in general practitioner clinics and nursing homes (Balmer, 2020). The basis of these actions was to take pressure off hospital staff providing critical services and to be flexible and adaptable while providing a valuable immersive learning experience. Despite the perceived risks of getting exposed to the coronavirus, desire to return to the clinical setting remains strong among students (Stokes, 2020; Compton et al., 2020).

However, uncertainty loomed to the length of the crisis as to when the students would be allowed back for proper clinical work. When ward work resumes, physical distancing and other prevention measures will further limit traditional clinical learning. The falling numbers of in-patients and restriction of number of students into wards and clinic rooms will further limit experiential learning. Disruption to scheduling, assessments, new intake and delayed internship and residency are inevitable (Choi et al., 2020; Akers, Blough and lyer, 2020). The medium term and long-term impact to this disruption adds to the uncertainty.

\section{Remedial measures}

Efforts by medical schools to mitigate this shortfall of clinical training have been varied. Many educational institutions adjusted quickly for remote delivery of lessons. Medical schools that already invested in technology prior to the crisis generally had a smoother transition to an online mode of learning.

As an immediate remedy and to keep students engaged, previous webcast links and online lectures were made available. Audio-dubbed lecture slides and online quizzes were quickly added (Lyons, 2020). Discussions boards, etutorials and online lectures were linked to the schools virtual learning portal (Veasuvalingam and Goodson 2020). Access to an online video library of patient encounters mitigated the loss of direct patient contact (Mian and Khan, 2020). Others have used videos to demonstrate clinical examination techniques (Al Hussona et al., 2020). Students were directed to large online resources such as YouTube videos and podcasts. Clinical students in Canada joined others to produce a weekly newsletter that directly responded to COVID-19 questions. (Boodman, Lee and Bullard, 2020). Additionally, webinars, case studies and discussion of examination questions supplemented the learning and deemed useful by students (Sandhu and de Wolf, 2020). The delivery was in both asynchronous and in live modes via virtual online communication platforms (e.g. Zoom ${ }^{\circledR}$, Microsoft Teams ${ }^{\circledR}$, Skype $\left.{ }^{\circledR}\right)$.

Previous studies that shown that tele-learning technologies have been shown to achieve comparable learning outcomes compared to traditional face-to-face models (Tomlinson et al., 2013). There are certain aspects of clinical experiential learning that cannot be replaced by online resources, but it does not imply a complete halt of learning opportunities.

These resources, despite many been excellent content may not plug straight in to fill the loss of clinical training without significant oversight by mentors. Although classroom-based teaching is more easily modified to an online format, hospital-based clinical learning is more challenging to replicate. While these serve to fill the cognitive learning, psychomotor and kinaesthetic skills are incompletely fulfilled.

Engaging in safer alternative yet essential nonclinical tasks offer valuable and relatively rare educational experiences while assisting the busier team members. Staffing patient hotlines, setting up virtual visits, telehealth sessions and assisting in public health awareness initiatives are some of tasks that gives a sense of contribution and continuity in the clinical space (Khamees et al., 2020; Abraham et al., 2020).

Barriers highlighted for remote e-learning were time constraints, poor technical skills, inadequate infrastructure and absence of institutional strategies (Sahi, Mishra and Singh, 2020). Compounding the challenges for both students and teachers are reliable and stable internet connectivity, economic data plans, vagaries of communication platform and nonconducive home-learning environment (Gona 2020). These are particularly formidable obstacles in low-resource settings where information and communications technology infrastructure are weak, and laptops or tablet devices are still unaffordable as the small-sized screen of a smartphone may not be an ideal device for long periods of viewing.

\section{Innovative solutions}

For years the disruption to medical education has been predicted with experienced medical 
educators experimenting several novel strategies (Poulton, 2011; Kim S, 2006). The forecast was for a gradual transformation with the encroachment of technology, not for a sudden adoption. As student numbers rose, hospital specialization advanced, reluctance by patients for students to learn on them increased, computer and online-based simulations of clinical scenarios appeared an ideal solution to overcome the challenges of limited exposure of students to real patients (Cook, Erwin and Triola, 2010).

Simulations, virtual clinical training, telemedicine are some of the alternative ways to complement traditional clinical education. Digital technologies, however sophisticated, are not standalones: guidance and support from teachers and mentors are still needed to augment the teaching and learning process. The lack of fidelity and realism with such learning methods, notwithstanding the cost of initial investment and training of trainers will hamper immediate transition.

Recently there has been increased use of simulation in health professional education (Okuda et al., 2009). Simulation can be viewed as an attractive solution providing a low-risk environment as minimising patient and learner risk is important in the current context and may address some of the shortfalls in practical competencies.

There is increased recognition that high-fidelity medical simulations which typically involves a high level of learner interaction with an authentic learning environment are educationally effective and simulation-based education complements medical education in patient care settings (Eckert, Volmerg and Friedrich, 2019; Horstmann, Horstmann and Renninger, 2011). Clinically oriented learning from virtual patients can promote the development of clinical reasoning and support competency-based education (Berman et al., 2016). Augmented reality helps to create authentic simulated experiences and virtual reality technology could transform and advance medical student learning (Pottle, 2019; McGrath et al., 2017). With the introduction of latest $5 G$ technology, the immersive experience is likely to be even more responsive and realistic.

Early attempts of some of these innovative methods adopted during this crisis have been described. The report of a consultant at Imperial College conducting a virtual ward round at St Mary's Hospital London, UK using Microsoft's HoloLens device for medical students to observe and listen to the interaction with the patients and see displayed images has caught the imagination of the medical world of education (Tapper, 2020).

The wearer of this untethered headset with a transparent lens - a mix-reality device, is able to send a secure live video feed to a computer screen or individual phones allowing students and the healthcare team to see everything the doctor does while remaining at a safe distance. The students appear to find the experience invaluable given the circumstances. These sessions can also be recorded for viewing later. The technology is not without its downsides as prolonged use may induce motion sickness and eye strain that may limit the duration of use (Wang et al., 2019).

A similar virtual bedside round to share diagnostic information using a low-cost solution with an iPad Pro and videoconferencing application was also well received by the attending students (Hofmann et al. 2020). Successful livestream of multiple different types of neurosurgical operations utilizing multiple video sources using inexpensive equipment via Zoom ${ }^{\circledR}$ to students has been reported and perceived to be satisfactory (Jack et al., 2020).

Such technology is scalable, reusable and suitable for many students with limited patient access. The tasks should be meaningful, transferrable to the real world as simulations are simply one technique of many that can promote student learning. It is up to medical schools to make the call as to which of these modalities should be added to the toolbox of clinical learning.

Telemedicine or telehealth is another established technology that allows patients to receive safe, rapid, and high-quality medical care remotely from a distance without physical contact through video or telephony (Ohannessian, 2015; Kruse, et al 2017). The modality has been thrust forward during the pandemic as an attractive option to provide remote consultation and patient monitoring without physical contact (Monaghesh and Hajizadeh, 2020; Hollander and Carr, 2020). Telehealth is not only for isolated communities as this pandemic has shown as these services are increasingly used to overcome physical distancing and lockdown measures in many developed countries (Smith et al., 2020). Several curricular activities such as taking a history and performing a virtual physical exam, a discussion of the possible diagnoses and potential diagnostic tests can be carried out in 
the presence of the attending physician or facilitator (lancu, Kemp and Alam, 2020).

However, these services are in the infancy in many developing countries and involve complex workflows that obviates its use for immediate adoption in the teaching environment.

Medical students who are trained in conventional methods of physical examination may have never been exposed to these technologies beforehand. Quick transition to this technology is not a feasible alternative for many at this point of time. With expanding wireless broadband technology and 5G services, homes and mobile individuals can be increasingly served through telehealth economically in the future. Medical schools may well embrace these modalities as part of a future curriculum in a changing landscape of delivery of healthcare.

\section{Future plans}

With the real prospect of face to face learning getting disrupted in the future, be it a second wave or travel or visa-related issue, online and virtual learning environments are likely to increasingly figure in the delivery of future curriculum. There is a need to rethink clinical education and plan to minimise the risks and shocks of future disruptions from design and quality through to ethics and economics as new technological advances are embraced into revised lesson plans. Time is opportune to take a serious look at unbundling and rebundling concepts of learning in order to exploit the rich resources available without fragmenting the identity of the institution or devaluing the student experience.

Several suggestions that have been proposed when transiting to online learning from face to face mode. These serve as stop gap measures that will maintain student engagement until clinical learning resumes. Preparing for the future new-normal workplace, designing and implementing virtual clinical examination, building online capacity, training stakeholders are some of the additional tasks for educational institutions to stay ahead and be responsive and not get caught flat-footed by future disruptions. Whatever changes that may be forced must be guided by the goal of improving patient care.

These new modalities however flexible or adoptable are unlikely to replace the rich experiential learning directly from the patient in the ward or clinic. The role model's behaviour at the bedside of a patient and the oral culture of storytelling by the patient are priceless snippets of the hidden curriculum. Campuses are sites of peer learning and rich social interactions and students can be lost in a digitized environment. The impact on both social dimensions of learning and the informal curriculum must be carefully weighed with technological adoption to avoid collateral damage. Curricula are generally slow to change, and this pandemic may be the change agent. The solutions should not to base choices on technological possibilities but on educational needs. At best, these innovations may supplement or mitigate the lost hours of clinical training and prepare the students, both novice and advanced beginner to make full use of the limited patient resources in these uncertain times.

\section{Conclusions}

This short review focused on the impact of clinical training of medical undergraduates affected by the Covid-19 crisis. The lack of preparedness by the global educational institutions for this scale of disruption has been noteworthy. The pedagogical actions taken to mitigate the loss of face to face clinical learning has been variable. Technology has enabled continuation of learning for the preclinical years but has not sufficiently catered to the needs of students in the clinical years. However, technology enabled learning will remain a formidable mode of undergraduate medical education in the post-COVID clinical environment. Examples of innovative technology solutions that engages the learner have been showcased during this crisis.

Clinical experience and human interaction face to face are extremely important facets for the practice of medicine and online learning cannot completely replace in-person live sessions. There is an urgent need for medical schools to identify, plan, design and evaluate appropriate immersive clinical experiences to mitigate against similar disruptions in the future.

\section{Conflicts of interest}

The author declares no conflict of interest.

\section{Acknowledgement}

I am grateful to Prof. Velayudhan Menon for reviewing the manuscript and for his useful suggestions.

\section{References}

AAMC. (2020). Important Guidance for Medical Students on Clinical Rotations During the Coronavirus (COVID-19) Outbreak. [online] 
Available at: https://www.aamc.org/newsinsights/press-releases/importantguidance-medical-students-clinicalrotations-during-coronavirus-covid-19outbreak. [Accessed April 17, 2020]

Abraham, H.N., Opara, I.N., Dwaihy, R.L., Acuff, C., Brauer, B., Nabaty, R. and Levine, D.L. (2020). Engaging Third-Year Medical Students on Their Internal Medicine Clerkship in Telehealth During COVID19. Cureus.

Akers, A., Blough, C. and lyer, M.S. (2020). COVID-19 implications on clinical clerkships and the residency application process for medical students. Cureus. 12(4), p.e7800.

Al Hussona, M., Maher, M., Chan, D., Micieli, J.A., Jain, J.D., Khosravani, H., Izenberg, A., Kassardjian, C.D. and Mitchell, S.B. (2020). The Virtual Neurologic Exam: Instructional Videos and Guidance for the COVID-19 Era. Canadian Journal of Neurological Sciences / Journal Canadien des Sciences Neurologiques, 47(5), pp.598-603.

Balmer, A.A., Crispian (2020). Italy rushes new doctors into service as coronavirus deaths rise above 2,500. Reuters. [online] 17 Mar. Available at: https://www.reuters.com/article/us-healthcoronavirus-italy-idUSKBN214245 [Accessed 23 Aug. 2020].

Berman, N.B., Durning, S.J., Fischer, M.R., Huwendiek, S. and Triola, M.M. (2016). The Role for Virtual Patients in the Future of Medical Education. Academic Medicine, 91(9), pp.1217-1222.

Boodman, C., Lee, S. and Bullard, J. (2020). Idle medical students review emerging COVID-19 research. Medical Education Online, 25(1), p.1770562.

British Medical Association COVID-19: early provisional registration for final year students. BMA, 2020. www.bma.org.uk/advice-andsupport/covid-19/your-contract/covid-19early-provisional-registration-for-final-yearstudents [Accessed 19 April 2020].

Choi, B., Jegatheeswaran, L., Minocha, A., Alhilani, M., Nakhoul, M. and Mutengesa, E. (2020). The impact of the COVID-19 pandemic on final year medical students in the United Kingdom: a national survey. BMC medical education. 20(1), p.206.
Compton, S., Sarraf-Yazdi, S., Rustandy, F. and Radha Krishna, L.K. (2020). Medical students' preference for returning to the clinical setting during the COVID-19 pandemic. Medical Education, 54: pp.943- 950.

Cook, D., Erwin, P. and Triola, M., 2010. Computerized Virtual Patients in Health Professions Education: A Systematic Review and Meta-Analysis. Academic Medicine, 85(10), pp.1589-1602.

Eckert, M., Volmerg, J.S. and Friedrich, C.M. (2019). Augmented Reality in Medicine: Systematic and Bibliographic Review. Journal of Medical Internet Research mHealth and uHealth, 7(4), p.e10967.

Gona, C.V., 2020. Online Final Medical School Exam in a Low-Income Country During COVID-19 Pandemic. International Journal of Medical Students, 8(2), pp.203-204.

MQA Guidelines on the delivery of higher education programmes during and post covid-19 movement control order (MCO) general guide. (2020 [online] Available at: https://www.mqa.gov.my/pv4/document/adv isoryNotes/Advisory\%20Note\%20No.\%201 $\% 202020 \% 20$ -

\%20PPPPPT\%20EngVer10.4.2020.pdf

[Accessed 23 Aug. 2020].

Hofmann, H., Harding, C., Youm, J., \& Wiechmann, W. (2020). Virtual bedside teaching rounds with patients with COVID19. Medical education, 10.1111/medu.14223. Advance online publication.

https://doi.org/10.1111/medu.14223

Hollander, J. E., \& Carr, B. G. (2020). Virtually Perfect? Telemedicine for Covid-19. The New England journal of medicine, 382(18), pp.1679-1681.

Horstmann, M., Horstmann, C. and Renninger, M. (2011). Case Creation and E-Learning in a Web-Based Virtual Department of Urology Using the INMEDEA Simulator. NephroUrology Monthly, 4(1), pp.356-362.

lancu, A.M., Kemp, M.T. and Alam, H.B. (2020). Unmuting Medical Students' Education: Utilizing Telemedicine During the COVID-19 Pandemic and Beyond. Journal of Medical Internet Research, 22(7), p.e19667.

Ing, E. B., Xu, Q. A., Salimi, A., \& Torun, N. (2020). Physician deaths from corona virus (COVID-19) disease. Occupational 
medicine (Oxford, England), 70(5), pp. 370374.

Jack, M.M., Gattozzi, D.A., Camarata, P.J. and Shah, K.J. (2020). Live-Streaming Surgery for Medical Student Education - Educational Solutions in Neurosurgery During the COVID-19 Pandemic. Journal of Surgical Education.

Khamees, D., Brown, C.A., Arribas, M., Murphey, A.C., Haas, M.R.C. and House, J.B. (2020). In Crisis: Medical Students in the COVID-19 Pandemic. AEM Education and Training, 4(3), pp.284-290.

Kim, S. (2006). The Future of e-Learning in Medical Education: Current Trend and Future Opportunity. Journal of Educational Evaluation for Health Professions, [online] 3, p.3. Available at: https://www.ncbi.nlm.nih.gov/pmc/articles/P MC2631188/pdf/jeehp-3-3.pdf [Accessed 4 Sep. 2020].

Kruse, C.S., Krowski, N., Rodriguez, B., Tran, L., Vela, J. and Brooks, M. (2017). Telehealth and patient satisfaction: a systematic review and narrative analysis. BMJ Open, [online] 7(8), p.e016242.

Lyons, K.M., Christopoulos, A. and Brock, T.P. (2020). Sustainable pharmacy education in the time of COVID-19. American journal of pharmaceutical education. 84(6), p.ajpe8088.

McGrath, J.L., Taekman, J.M., Dev, P., Danforth, D.R., Mohan, D., Kman, N., Crichlow, A. and Bond, W.F. (2017). Using Virtual Reality Simulation Environments to Assess Competence for Emergency Medicine Learners. Academic Emergency Medicine, 25(2), pp.186-195.

Medical Deans of Australia and New Zealand. Principles for medical students' safe and useful roles in the COVID-19 health workforce, 2020. https://medicaldeans.org.au/md/2020/03/20 20-March-20_principles-for-medicalstudent-roles-in-COVID-19-healthworkforce.pdf

Mian, A. and Khan, S. (2020). Medical education during pandemics: a UK perspective. BMC Medicine, 18(1).

Monaghesh, E. and Hajizadeh, A. (2020). The role of telehealth during COVID-19 outbreak: a systematic review based on current evidence. BMC Public Health, 20(1).
Ohannessian, R. (2015). Telemedicine: Potential applications in epidemic situations. European Research in Telemedicine / La Recherche Européenne en Télémédecine, 4(3), pp.95-98.

Okuda, Y., Bryson, E.O., DeMaria, S., Jacobson, L., Quinones, J., Shen, B. and Levine, A.I. (2009). The Utility of Simulation in Medical Education: What Is the Evidence? Mount Sinai Journal of Medicine: A Journal of Translational and Personalized Medicine, 76(4), pp.330-343.

Pottle, J. (2019). Virtual reality and the transformation of medical education. Future Healthcare Journal, [online] 6(3), pp.181185.

Poulton, T., \& Balasubramaniam, C. (2011). Virtual patients: a year of change. Medical Teacher, 33(11), pp. 933-937.

Sahi, P.K., Mishra, D. and Singh, T. (2020). Medical Education Amid the COVID-19 Pandemic. Indian Pediatrics, 57(7), pp.652657.

Samarasekera, D.D., Goh, D.L.M., Yeo, S.P., Ngiam, N.S.P., Aw, M.M., Lim, M.M., Pillai, S., Lee, S.S., Mahadevan, M., Kow, A., Chong, Y.S. and Lau, T.C. (2020). Response and Lessons Learnt Managing the COVID-19 Crisis by School of Medicine, National University of Singapore. MedEdPublish, 9(1).

Sandhu, P. and de Wolf, M. (2020). The impact of COVID-19 on the undergraduate medical curriculum. Medical Education Online, 25(1), p.1764740.

Smith, A.C., Thomas, E., Snoswell, C.L., Haydon, H., Mehrotra, A., Clemensen, J. and Caffery, L.J. (2020). Telehealth for global emergencies: Implications for coronavirus disease 2019 (COVID19). Journal of Telemedicine and Telecare, 26(5), p.1357633X2091656.

Stokes, D.C. (2020). Senior medical students in the COVID-19 response: An opportunity to be proactive. Academic Emergency Medicine, 27(4), pp.343-345.

Tapper, J. (2020). London hospital starts virtual ward rounds for medical students. The Guardian. [online] 4 Jul. Available at: https://www.theguardian.com/society/2020/j ul/04/london-hospital-starts-virtual-wardrounds-for-medical-students [Accessed 18 Sep. 2020]. 
Tomlinson, J., Shaw, T., Munro, A., Johnson, R., Madden, D.L., Phillips, R. and McGregor, D. (2013). How does telelearning compare with other forms of education delivery? A systematic review of tele-learning educational outcomes for health professionals. New South Wales Public Health Bulletin, 24(2), p.70.

Veasuvalingam B, Goodson M, 2020, 'Falling back on technology mindfully during COVID19 pandemic: NUMed campus experience', MedEdPublish, 9, [1], 102,

Wang, Y., Zhai, G., Chen, S., Min, X., Gao, Z. and Song, X. (2019). Assessment of eye fatigue caused by head-mounted displays using eye-tracking. BioMedical Engineering OnLine, 18(1).

World Health Organization. WHO DirectorGeneral's opening remarks at the media briefing on COVID-19-11 March 2020: https://www.who.int/dg/speeches/detail/who -director-general-s-opening-remarks-at-themedia-briefing-on-covid-19---11-March2020. [Accessed 18 April 2020]. 